\title{
Short communication: Follicle superstimulation before ovum pick-up for in vitro embryo production in Holstein cows
}

\author{
Louise H. Oliveira, ${ }^{*}$ Carlos P. Sanches, † Adriano S. Seddon,‡ Marcio B. Veras,§ Flávio A. Lima,§ \\ Pedro L. J. Monteiro Jr, ${ }^{*}$ Milo C. Wiltbank,\# and Roberto Sartori ${ }^{* 1}$ \\ *Department of Animal Science, University of São Paulo, Piracicaba, SP 13418-900 Brazil \\ †Department of Animal Production, São Paulo State University, Botucatu, SP 18168-000 Brazil \\ $\ddagger$ Alcance Rural, Itapeva, SP 18400-970 Brazil \\ §Central Pioneiros, Carambeí, PR 84145-000 Brazil \\ \#Department of Dairy Science, University of Wisconsin-Madison, Madison 53706
}

ABSTRACT

The objective was to evaluate in vitro embryo production (IVEP) in nonlactating Holstein cows after ovarian superstimulation. Cows were randomly assigned in a crossover design to 1 of 2 groups: control $(\mathrm{n}=35)$, which was not synchronized and not treated with hormones before ovum pick-up (OPU), or hormone-treated $(\mathrm{n}=35)$, in which wave emergence was synchronized and animals treated with porcine (p)FSH in the presence of norgestomet before OPU. In the hormone-treated group, all follicles $\geq 7 \mathrm{~mm}$ in diameter were aspirated for synchronization of wave emergence and cows received a norgestomet ear implant. After 36 $\mathrm{h}$, treatment with p-FSH ( 6 doses of $40 \mathrm{mg}$ each, $12 \mathrm{~h}$ apart, i.m.) started. Ovum pick-up from follicles $>2$ $\mathrm{mm}$ in diameter was performed $44 \mathrm{~h}$ after the last pFSH (coasting). Then, IVEP was performed. The total number of cumulus-oocyte complexes recovered (16.0 vs. $20.5 \pm 2.2$ ) and number of grades I to III (viable) oocytes (10.7 vs. $12.3 \pm 1.6)$ did not differ between hormone-treated and control groups Additionally, no differences were found in the number of blastocysts per cow per OPU (3.0 vs. $2.6 \pm 0.5$ ) or in blastocyst rates (17.1 vs. $12.2 \pm 2.4 \%$ ) between hormone-treated and control, respectively. Thus, in this study, ovarian follicle superstimulation with p-FSH followed by coasting in nonlactating Holstein cows that had synchronization of wave emergence and progestin supplementation did not improve oocyte quality or IVEP compared to no hormonal treatment.

Key words: biotechnology, blastocyst, cattle, oocyte

Received April 11, 2016

Accepted June 7, 2016.

${ }^{1}$ Corresponding author: robertosartori@usp.br

\section{Short Communication}

In dairy cows, embryo transfer (ET) is commonly used as a tool for genetic improvement. In addition, ET can be used to enhance reproductive efficiency of herds particularly in cows in specific physiological conditions such as heat stress (Demetrio et al., 2006; Stewart et al., 2011). Embryo production by multiple ovulation and ET is widely used around the world, but the variability in response to the superstimulatory treatments remains an important limitation (Galli et al., 2003). An alternative reproductive biotechnology for embryo production is in vitro embryo production (IVEP). This biotechnology allows production of a large number of embryos from high genetic potential donors during a shortened period (Pontes et al., 2009) and allows the use of sex-sorted sperm without substantially compromising embryo production (Zhang et al., 2003; Carvalho et al., 2010). In North America, use of IVEP has dramatically increased during the last few years (Perry, 2015) probably because of the improvements in genetics, reproductive efficiency, and sex ratio of offspring that can be achieved with this technique. In Brazil, IVEP has been primarily used for Bos indicus beef cattle because of their greater antral follicle counts and therefore greater oocyte yield per collection than observed in Bos taurus (Sartori et al., 2016). However, use of IVEP has recently increased dramatically in dairy cattle in Brazil and other Latin American countries.

The successful implementation of an IVEP program depends on many factors including genetics of the donor, vacuum pressure during aspiration, needle type during ovum pick-up (OPU), and number of follicles present (Bols et al., 1997; Ward et al., 2000). These factors may influence the quality of oocytes collected, as determined visually, or the success of in vitro maturation and fertilization of oocytes or subsequent in vitro embryo development, as determined by number, 
quality, and stage of the resulting embryos. In addition, some studies have indicated that stage of the follicular wave or follicle size may affect the success of IVEP after OPU (Hendriksen et al., 2004; Machatkova et al., 2004). For example, in cows on a random day of the estrous cycle, oocytes were more likely to be classified as healthy if they were from larger $(>8 \mathrm{~mm} ; 70 \%)$ than medium (6 to $8 \mathrm{~mm} ; 33 \%$ ) or smaller $(<6 \mathrm{~mm} ; 12 \%)$ follicles (Carolan et al., 1996). Furthermore, cows that were treated with FSH had a greater proportion of follicles with intermediate diameters $(>6$ and $<10 \mathrm{~mm})$ compared with cows from the control group (Goodhand et al., 1999). Thus, it follows logically that hormonal treatments during growth of the follicular wave before OPU could be used to presynchronize follicles to a more ideal stage for IVEP.

Nevertheless, use of follicular aspiration or treatment with estradiol benzoate had no significant effect on oocyte number or quality, cleavage rate, or blastocyst rate or number (Ramos et al., 2010). Similarly, oocytes collected from cows at different phases of the estrous cycle had similar developmental capacity (de Wit et al., 2000). However, in another study, greater blastocyst rates were found for oocytes collected from follicles in the growth rather than dominance phase of a follicular wave (Machatkova et al., 2004). In contrast, although superstimulation with FSH increased the number of large, healthy follicles in the growth phase, FSH treatment reduced the blastocyst development rates in oocytes collected from these follicles (Blondin et al., 1996). Nonetheless, Blondin et al. (2002) suggested that superstimulation should be combined with a period of "coasting" (time between last FSH and OPU) before OPU. Coasting for $48 \mathrm{~h}$ produced more follicles of 5 to $10 \mathrm{~mm}$ compared with only $33 \mathrm{~h}$ of coasting. Further, addition of an LH surge $6 \mathrm{~h}$ before OPU increased blastocyst production in oocytes collected after $33 \mathrm{~h}$ of coasting but not in oocytes collected after $48 \mathrm{~h}$ of coasting (Blondin et al., 2002). Although blastocyst rates were exceedingly high in this study, no comparisons were made to oocytes from cows without FSH superstimulation. Several other studies have evaluated the role of FSH and subsequent coasting on oocyte quality and blastocyst production, with generally positive effects in Holstein cattle (Nivet et al., 2012) but no significant effects on IVEP success in Nelore cattle (Monteiro et al., 2010).

The substantial increase in IVEP during the last few years, particularly in North and South America, makes evaluation of the effects of superstimulation on IVEP success of substantial practical interest. In addition, superstimulation has become routine for many IVEP practitioners in the United States, but it has been used very little in South America where a substantial number of the global IVEP embryos are produced (Blondin, 2015). The experimental design and statistical power for evaluating this practical question is important because of the substantial variability between cows in antral follicle numbers and potentially in developmental capacity of oocytes collected from different cows. Therefore, the objective of the present study was to evaluate IVEP in nonlactating Holstein cows treated with a protocol very similar to that described by Nivet et al. (2012) in direct comparison to performing OPU in cows not submitted to any synchronization or hormonal treatment. A crossover experimental design was used so that each individual cow was subjected to both treatments to increase statistical power of the study. Based on previous research, our hypothesis was that Holstein cattle treated with FSH after follicle wave synchronization and with a norgestomet implant and then having a coasting period of $44 \mathrm{~h}$ before OPU would have greater blastocyst production than cows that had OPU without synchronization or hormone treatment.

Thirty-five nonlactating multiparous Holstein cows $[5.8 \pm 1.78$ (mean $\pm \mathrm{SD}$ ) years old and BCS of $3.2 \pm$ 0.30 (mean $\pm \mathrm{SD})$ ] were used in the study performed in Brazil. Cows were housed in free-stall barns equipped with sprinklers and fans and were fed ad libitum a TMR-based diet of corn silage and corn and soybean meal-based concentrate with minerals and vitamins, which was balanced to meet or exceed the nutritional requirements of nonlactating dairy cows (NRC, 2001).

Cows were randomly assigned in a crossover design to the following experimental groups: control $(\mathrm{n}=35)$, in which cows were not synchronized and not treated with hormones before OPU, or hormone-treated $(\mathrm{n}=35)$, in which, $36 \mathrm{~h}$ after OPU for follicle wave synchronization and insertion of a norgestomet implant (Crestar, MSD, São Paulo, Brazil), cows were treated with porcine (p)-FSH (Folltropin-V, Bioniche Animal Health, ON, Canada) and were subjected to OPU sessions. Fourteen days were allowed between periods. In the hormone-treated group, all ovarian follicles $\geq 7 \mathrm{~mm}$ in diameter were aspirated for synchronization of follicle wave emergence and cows received a norgestomet ear implant. Thirty-six hours later, the treatment with 240 mg of p-FSH i.m. was started, which was administered in 6 doses of $40 \mathrm{mg}$ each, $12 \mathrm{~h}$ apart. The OPU was performed $44 \mathrm{~h}$ after the last p-FSH (coasting), when the implant was removed (Figure 1).

Before the OPU sessions, cows had their perineal area cleaned with water and $70 \%$ ethanol. Epidural anesthesia was performed with $5 \mathrm{~mL}$ of $2 \%$ lidocaine hydrochloride (Xylestesin, Cristália, Itapira, Brazil). All follicles $>2 \mathrm{~mm}$ in diameter were aspirated by ul- 


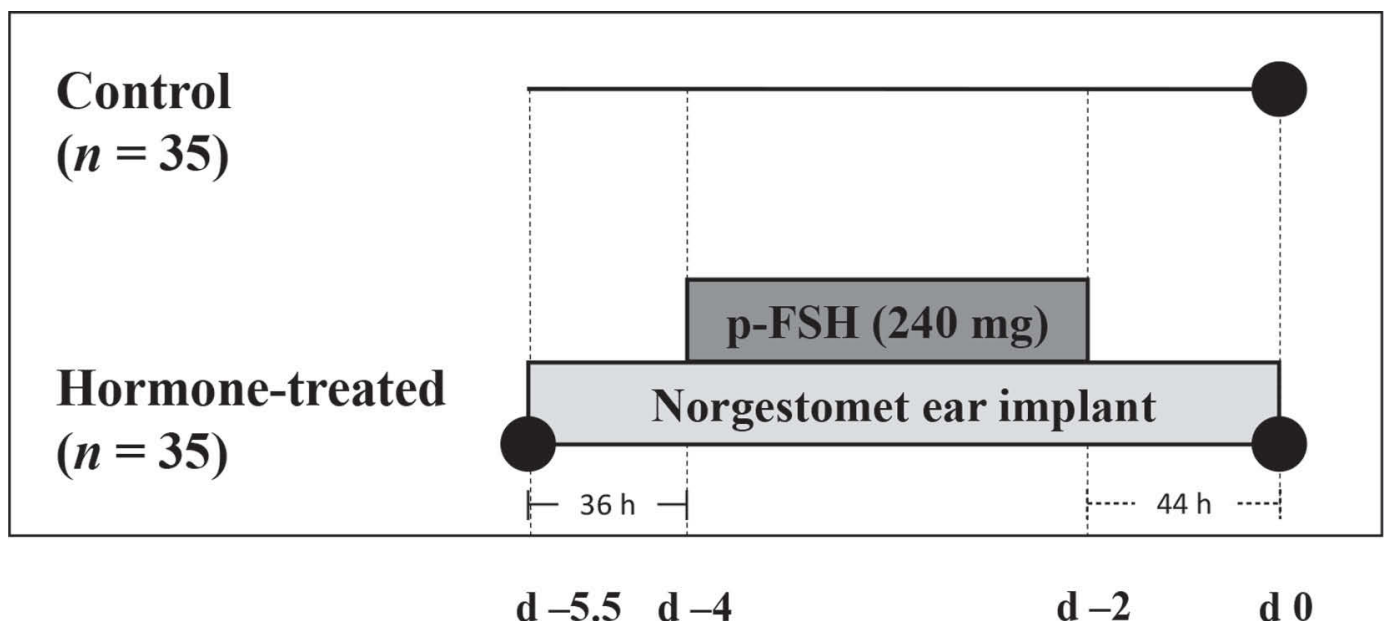

Figure 1. Diagram of activities for the experiment. Control: nonlactating Holstein cows not synchronized and not treated with hormones before ovum pick-up (OPU, $\mathbf{0}$; 0 ). Hormone-treated: donors received a norgestomet ear implant and follicles $\geq 7 \mathrm{~mm}$ in diameter were aspirated for wave synchronization (day -5.5). Treatment with $240 \mathrm{mg}$ of porcine (p)-FSH, i.m., began $36 \mathrm{~h}$ later on $\mathrm{d}-4$ (6 treatments with 40 $\mathrm{mg}$ of p-FSH each, $12 \mathrm{~h}$ apart). Ovum pick-up was performed $44 \mathrm{~h}$ after the last FSH injection. Immediately before OPU, the ear implant was removed. On $\mathrm{d} 0$, in both groups, all follicles $\geq 2.5 \mathrm{~mm}$ in diameter were aspirated.

trasound (DP 2200; Mindray, Shenzhen, China), which was equipped with a $7.5-\mathrm{MHz}$ convex array transducer and coupled to a vaginal aspiration guide containing a stainless steel needle guide connected to a vacuum system (BV 003d, Watanabe Tecnologia Aplicada, Cravinhos, Brazil). The IVEP (including the OPU sessions, in vitro maturation, in vitro fertilization, and in vitro culture) was performed using similar techniques as those described by Monteiro et al. (2015). Blastocyst rate was evaluated on the seventh day of embryo culture.

Continuous data were analyzed by using the Mixed procedure of SAS (System for Windows, Version 9.3; SAS Institute Inc., Cary, NC), and binomial data were analyzed by the Glimmix procedure of SAS. The variables evaluated were the total number of recovered cumulus-oocyte complexes (COC), number and percentage of viable $\mathrm{COC}$, blastocyst rate, and the proportion of cows that produced embryos. The model included the fixed effects of treatment and bulls, and the random effect of period. Differences of $P \leq 0.05$ were considered significant and differences of $0.05<P$ $\leq 0.10$ were considered tendencies. Data are shown as least squares means \pm SEM.

The success of IVEP is directly related to the number and the quality of COC harvested by OPU (Baruselli et al., 2012). The COC from larger (>8 mm in diameter) follicle sizes are healthier (Carolan et al., 1996), and p-FSH treatment increases the proportion of large follicles and the number of produced embryos (Goodhand et al., 1999). Another factor that can increase the blastocyst rate is the ideal coasting period (Nivet et al., 2012). Nonetheless, the results of this experiment using 70 OPU sessions and a statistically powerful, crossover experimental design provided no evidence to support our primary hypotheses that Holstein cattle would have improved oocyte number and quality and blastocyst production from oocytes collected after follicle wave synchronization, hormone treatment, and coasting period of $44 \mathrm{~h}$ compared to oocytes collected from follicles not subjected to synchronization or hormonal treatments (Table 1).

For example, the total number of COC recovered and number of viable oocytes were similar between hormone-treated and control groups (Table 1). Additionally, the proportion of viable COC (viable COC per total number of COC recovered) did not increase. Similarly, lactating and nonlactating Holstein cows treated with 4 doses of p-FSH (total of $200 \mathrm{mg}, 12 \mathrm{~h}$ apart) did not have increased oocyte retrieval in comparison to synchronized cows not treated with p-FSH (Vieira et al., 2014). Another study using 6 doses of FSH failed to increase the number of recovered oocytes (Goodhand et al., 1999). Independent of treatments, the average number of COC recovered per cow per OPU session in the present study (18.3) was greater than what has been reported by others (Hasler et al., 1995; Bousquet et al., 1999; Pontes et al., 2010; Vieira et al., 2014).

We also evaluated whether hormonal treatment would increase embryo production per OPU session or blastocyst rate. In the present study, we were unable to detect any differences in the number of blastocysts per 
Table 1. Results (LSM \pm SEM) of cumulus-oocyte complexes (COC) recovery and blastocyst production of nonlactating Holstein cows from the control group: not synchronized and not treated with hormones before ovum pick-up (OPU) or hormone-treated: wave emergence synchronized and treated with porcine-FSH in the presence of norgestomet before OPU

\begin{tabular}{|c|c|c|c|c|}
\hline Item & $\begin{array}{l}\text { Control } \\
(\mathrm{n}=35)\end{array}$ & $\begin{array}{c}\text { Hormone-treated } \\
\quad(\mathrm{n}=35)\end{array}$ & SEM & $P$-value \\
\hline Total COC recovered, no. & 719 & 562 & - & - \\
\hline Total COC recovered/cow per OPU, no. & 20.5 & 16.0 & 2.20 & 0.15 \\
\hline Viable COC recovered/cow per OPU, no. & 12.3 & 10.7 & 1.64 & 0.49 \\
\hline Viable COC, $\%$ & 57.0 & 62.2 & 4.50 & 0.28 \\
\hline Total blastocysts, no. & 94 & 105 & - & - \\
\hline Blastocysts/viable COC, $\%$ & 21.9 & 28.6 & 3.76 & 0.28 \\
\hline OPU sessions yielding blastocysts, \% (no./no.) & $74.3(26 / 35)$ & $80.0(28 / 35)$ & - & 0.67 \\
\hline
\end{tabular}

cow per OPU or in the rates of blastocyst production (Table 1). Some studies have associated improvements in blastocyst rate with increased follicle size and oocyte developmental potential following p-FSH treatment (Sendag et al., 2008; Vieira et al., 2014). Another study (Goodhand et al., 1999) obtained a slightly positive effect on the number of transferable embryo in heifers treated with FSH for $3 \mathrm{~d}$ before aspiration. Lonergan et al. (1994) reported that the administration of 6 injections of p-FSH beginning $3 \mathrm{~d}$ before slaughter significantly increased the proportion of $>6$-mm-diameter follicles in the ovaries in comparison to the untreated group; however, no difference was observed in terms of cleavage rate or blastocyst yield between groups for any of the individual follicle diameter categories $(2-6$ $\mathrm{mm}$ or $>6 \mathrm{~mm})$ or overall. Additionally, according to Seneda et al. (2001), oocyte quality, cleavage rate, and blastocyst development did not differ between different follicle sizes in beef cattle. Finally, FSH treatment may be used to increase the numbers of follicles in the correct size categories and even growth phase but still may not provide an ideal environment for the oocyte to acquire developmental competence (Blondin et al., 2002; Mundim et al., 2009).

The coasting period between the last FSH injection and OPU has been suggested to improve blastocyst rates (Blondin et al., 1997; Nivet et al., 2012) by increasing the COC developmental competence (Blondin et al., 1997). According to Blondin et al. (1997), follicles that enter phases of later dominance or early atresia should provide COC from an ideal follicular environment to acquire developmental competence in vitro (Blondin et al., 2002). Interestingly, the number of embryos per cow per OPU session in the present study (2.8) was greater than what was described by Hasler et al. $(1995)(<1.0)$ and slightly greater that what was described by Pontes et al. (2010) (2.1). In nonlactating Holstein cows, the nontreated group from Vieira et al. (2014) had simi- lar (2.7) results to the present study; however, when administered p-FSH, they obtained a greater number of embryos (4.4). It is possible that the variability in results among authors is due to different IVEP systems employed or different antral follicle counts of the cows used in the studies.

Several studies have been conducted (Hendriksen et al., 2004; Machatkova et al., 2004; Gimenes et al., $2010,2015)$ to determine the ideal follicular phase to maximize the performance of OPU. Machatkova et al. (2004) found that the mean number of embryos per donor and the development rate of oocytes into blastocysts were greater in the growth phase than in the dominant phase. However, Gimenes et al. (2015) found that OPU done at different times of a synchronized follicle wave $(1,3$, or $5 \mathrm{~d}$ after expected emergence) did not influence the number of follicles or oocytes or blastocyst production in Nelore or Holstein heifers. According to Hendriksen et al. (2004), during the different stages of follicle development, growing follicles and other follicles in various degrees of atresia are always present. Further, Ramos et al. (2010) also found no effect on numbers of viable oocytes and rates of blastocyst production when Simmental $\times$ Nelore crossbred beef heifers had their follicles aspirated once or twice a week. These studies are in agreement with our results that show similar efficiency of IVEP regardless of the follicular phase.

Based on the results presented, we found no evidence from this study that ovarian follicle stimulation with p-FSH after wave synchronization and norgestomet implant combined with a coasting period increased any measured variable of IVEP success in high oocyteyielding nonlactating Holstein cows. It seems prudent for other investigators to carefully examine the efficacy of this protocol in different experimental circumstances, particularly given the extensive use of these methods in the ET industry. 


\section{ACKNOWLEDGMENTS}

We acknowledge the financial support from São Paulo Research Foundation (FAPESP; São Paulo, Brazil), Coordination for the Improvement of Higher Education Personnel (CAPES; Brasilia, Brazil), and the Brazilian National Council for Scientific and Technological Development (CNPq, Brasilia, Brazil).

\section{REFERENCES}

Baruselli, P. S., M. F. Sa, R. M. Ferreira, J. N. S. Sales, L. U. Gimenes, L. M. Vieira, M. F. Mendanha, and G. A. Bo. 2012. Manipulation of follicle development to ensure optimal oocyte quality and conception rates in cattle. Reprod. Domest. Anim. 47:134-141.

Blondin, P. 2015. Status of embryo production in the world. Anim. Reprod. 12:356-358.

Blondin, P., D. Bousquet, H. Twagiramungu, F. Barnes, and M. A. Sirard. 2002. Manipulation of follicular development to produce developmentally competent bovine oocytes. Biol. Reprod. 66:38-43.

Blondin, P., K. Coenen, L. A. Guilbault, and M. A. Sirard. 1996. Superovulation can reduce the developmental competence of bovine embryos. Theriogenology 46:1191-1203.

Blondin, P., L. A. Guilbault, and M. A. Sirard. 1997. The time interval between FSH-P administration and slaughter can influence the developmental competence of beef heifer oocytes. Theriogenology 48:803-813.

Bols, P. E. J., M. T. Ysebaert, A. VanSoom, and A. deKruif. 1997. Effects of needle tip bevel and aspiration procedure on the morphology and developmental capacity of bovine compact cumulus oocyte complexes. Theriogenology 47:1221-1236.

Bousquet, D., H. Twagiramungu, N. Morin, C. Brisson, G. Carboneau, and J. Durocher. 1999. In vitro embryo production in the cow: An effective alternative to the conventional embryo production approach. Theriogenology 51:59-70.

Carolan, C., P. Lonergan, P. Monget, D. Monniaux, and P. Mermillod. 1996. Effect of follicle size and quality on the ability of follicular fluid to support cytoplasmic maturation of bovine oocytes. Mol. Reprod. Dev. 43:477-483.

Carvalho, J. O., R. Sartori, G. M. Machado, G. B. Mourao, and M. A. N. Dode. 2010. Quality assessment of bovine cryopreserved sperm after sexing by flow cytometry and their use in in vitro embryo production. Theriogenology 74:1521-1530.

de Wit, A. A., Y. A. Wurth, and T. A. Kruip. 2000. Effect of ovarian phase and follicle quality on morphology and developmental capacity of the bovine cumulus-oocyte complex. J. Anim. Sci. 78:1277-1283.

Demetrio, D. G. B., R. M. Santos, C. G. B. Demetrio, C. A. Rodrigues, and J. L. M. Vasconcelos. 2006. Factors affecting conception of AI or ET in lactating cows. J. Anim. Sci. 84:207-208.

Galli, C., R. Duchi, G. Crotti, P. Turini, N. Ponderato, S. Colleoni, I. Lagutina, and G. Lazzari. 2003. Bovine embryo technologies. Theriogenology 59:599-616.

Gimenes, L. U., M. L. Ferraz, A. Araujo, P. F. Neto, M. R. Chiarati, L. G. Mesquita, J. S. P. Arango, M. Raposo, D. C. Souza, G. D. Calomeni, R. Gardinal, C. L. V. Rodriguez, L. A. Trinca, F. V. Meirelles, and P. S. Baruselli. 2010. Ovum pick-up at different times of a synchronized follicular wave did not affect IVP in Bos indicus, Bos taurus, or Bubalus bubalis. Reprod. Fertil. Dev. 22:293-294.

Gimenes, L. U., M. L. Ferraz, P. Fantinato-Neto, M. R. Chiaratti, L. G. Mesquita, M. F. Sa Filho, F. V. Meirelles, L. A. Trinca, F. P. Renno, Y. F. Watanabe, and P. S. Baruselli. 2015. The interval between the emergence of pharmacologically synchronized ovarian follicular waves and ovum pickup does not significantly affect in vitro embryo production in Bos indicus, Bos taurus, and Bubalus bubalis. Theriogenology 83:385-393.
Goodhand, K. L., R. G. Watt, M. E. Staines, J. S. M. Hutchinson, and P. J. Broadbent. 1999. In vivo oocyte recovery and in vitro embryo production from bovine donors aspirated at different frequencies or following FSH treatment. Theriogenology 51:951-961.

Hasler, J. F., W. B. Henderson, P. J. Hurtgen, Z. Q. Jin, A. D. McCauley, S. A. Mower, B. Neely, L. S. Shuey, J. E. Stokes, and S. A. Trimmer. 1995. Production, freezing and transfer of bovine IVF embryos and subsequent calving results. Theriogenology 43:141152

Hendriksen, P. J. M., W. N. M. Steenweg, J. C. Harkema, J. S. Merton, M. M. Bevers, P. Vos, and S. J. Dieleman. 2004. Effect of different stages of the follicular wave on in vitro developmental competence of bovine oocytes. Theriogenology 61:909-920.

Lonergan, P., P. Monaghan, D. Rizos, M. P. Boland, and I. Gordon. 1994. Effect of follicle size on bovine oocyte quality and developmental competence following maturation, fertilization, and culture in vitro. Mol. Reprod. Dev. 37:48-53.

Machatkova, M., K. Krausova, E. Jokesova, and M. Tomanek. 2004. Developmental competence of bovine oocytes: Effects of follicle size and the phase of follicular wave on in vitro embryo production. Theriogenology 61:329-335.

Monteiro, F. M., M. M. G. Ferreira, J. R. Potiens, B. G. Eberhardt, L. A. Trinca, and C. M. Barros. 2010. Influence of superovulatory protocols on in vitro production of Nellore (Bos indicus) embryos. Reprod. Domest. Anim. 45:860-864.

Monteiro, P. L. J. Jr., A. B. Nascimento, G. C. S. Pontes, G. O Fernandes, L. F. Melo, M. C. Wiltbank, and R. Sartori. 2015. Progesterone supplementation after ovulation: Effects on corpus luteum function and on fertility of dairy cows subjected to AI or ET. Theriogenology 84:1215-1224.

Mundim, T. C. D., A. F. Ramos, R. Sartori, M. A. N. Dode, E. O Melo, L. F. S. Gomes, R. Rumpf, and M. M. Franco. 2009. Changes in gene expression profiles of bovine embryos produced in vitro, by natural ovulation, or hormonal superstimulation. Genet. Mol. Res. 8:1398-1407.

NRC. 2001. Nutrient Requirements of Dairy Cattle. 7th rev. ed. Natl. Acad. Sci., Washington, DC.

Nivet, A.-L., A. Bunel, R. Labrecque, J. Belanger, C. Vigneault, P. Blondin, and M.-A. Sirard. 2012. FSH withdrawal improves developmental competence of oocytes in the bovine model. Reproduction 143:165-171.

Perry, G. 2015. 2014 Statistics of embryo collection and transfer in domestic farm animals. Embryo Transfer Newsl. 33:9-18.

Pontes, J. H. F., I. Nonato-Junior, B. V. Sanches, J. C. Ereno-Junior, S. Uvo, T. R. R. Barreiros, J. A. Oliveira, J. F. Hasler, and M. M. Seneda. 2009. Comparison of embryo yield and pregnancy rate between in vivo and in vitro methods in the same Nelore (Bos indicus) donor cows. Theriogenology 71:690-697.

Pontes, J. H. F., K. C. F. Silva, A. C. Basso, A. G. Rigo, C. R. Ferreira, G. M. G. Santos, B. V. Sanches, J. P. F. Porcionato, P. H. S. Vieira, F. S. Faifer, F. A. M. Sterza, J. L. Schenk, and M. M. Seneda. 2010. Large-scale in vitro embryo production and pregnancy rates from Bos taurus, Bos indicus, and indicus-taurus dairy cows using sexed sperm. Theriogenology 74:1349-1355.

Ramos, A. F., R. Rumpf, J. U. Camara, M. R. Mollo, I. Pivato, A. P. Marques Jr., and R. Sartori. 2010. Effect of follicular wave synchronization on in vitro embryo production in heifers. Anim. Reprod. Sci. 117:201-207.

Sartori, R., L. U. Gimenes, P. L. J. Monteiro Jr., L. F. Melo, P. S. Baruselli, and M. R. Bastos. 2016. Metabolic and endocrine differences between Bos taurus and Bos indicus females that impact the interaction of nutrition with reproduction. Theriogenology $86: 32-40$.

Sendag, S., Y. Cetin, M. Alan, K.-G. Hadeler, and H. Niemann. 2008. Effects of eCG and FSH on ovarian response, recovery rate and number and quality of oocytes obtained by ovum pick-up in Holstein cows. Anim. Reprod. Sci. 106:208-214.

Seneda, M. M., C. R. Esper, J. M. Garcia, J. A. de Oliveira, and R. Vantini. 2001. Relationship between follicle size and ultrasoundguided transvaginal oocyte recovery. Anim. Reprod. Sci. 67:37-43 
Stewart, B. M., J. Block, P. Morelli, A. E. Navarette, M. Amstalden, L. Bonilla, P. J. Hansen, and T. R. Bilby. 2011. Efficacy of embryo transfer in lactating dairy cows during summer using fresh or vitrified embryos produced in vitro with sex-sorted semen. J. Dairy Sci. 94:3437-3445

Vieira, L. M., C. A. Rodrigues, A. C. Netto, B. M. Guerreiro, C. R. A. Silveira, R. J. C. Moreira, M. F. Sa, G. A. Bo, R. J. Mapletoft, and P. S. Baruselli. 2014. Superstimulation prior to the ovum pickup to improve in vitro embryo production in lactating and nonlactating Holstein cows. Theriogenology 82:318-324.
Ward, F. A., P. Lonergan, B. P. Enright, and M. P. Boland. 2000. Factors affecting recovery and quality of oocytes for bovine embryo production in vitro using ovum pick-up technology. Theriogenology 54:433-446.

Zhang, M., K. H. Lu, and G. E. Seidel. 2003. Development of bovine embryos after in vitro fertilization of oocytes with flow cytometrically sorted, stained and unsorted sperm from different bulls. Theriogenology 60:1657-1663. 